\title{
Teaching Enhancement through Constructive Alignment
}

\author{
Camilo Escaran Jr. * \\ Jose L. Pena ** \\ Yolanda C. Sayson ** \\ Ily E. Abella ** \\ Mauro Allan P. Amparado **
}

mapamparado@gmail.com

\section{* University of Cebu Maritime Education and Training Center, Cebu City, Cebu, Philippines ** University of Cebu, Cebu City, Cebu, Philippines}

\section{Abstract}

This study investigated the extent of application of Constructive Alignment by the Instructors handling navigation courses and its implications to the implementation of Outcomesbased Education at the classroom level. The study utilized the descriptive-correlational design. The instrument used was a questionnaire accomplished by 23 instructors teaching navigation courses. The questionnaire was filled out by the instructor as a reflective process on how he will conduct his classes for the day. Observations, rubrics, and interviews with the instructors and students were conducted to evaluate the intended learning outcomes, learning activities, teaching methods, and assessment methods in the light of Constructive Alignment Theory.

The findings revealed that the majority of the instructors were bachelor degree holders, regular employees, with 1-5 years teaching experience, 16-20 years of sea experience, holders of second mate license, and has not attended any Constructive Alignment seminar. Constructive Alignment was applied in teaching methods, but less applied in intended learning outcomes, 
learning activities, and assessment methods. There was a significant relationship between seminars attended related to Constructive Alignment and the extent of application of Constructive Alignment.

In conclusion, skills and knowledge can best be taught through performances using Constructive Alignment in teaching. Nautical Instructors should focus more on learning outcomes in teaching navigation courses.

Keywords: Intended learning outcomes, Navigation courses, Constructive Alignment, Teaching methods, Philippines

Recommended citation: Escaran Jr., C., Pena, J. L., Sayson, Y. C., Abella, I. E. \& Amparado, M. A. P. (2015). Teaching Enhancement through Constructive Alignment. Journal of Research in Multidisciplinary Studies, 2(1), 92-100. 